\title{
No Man's Land: Reading Travel Accounts In Pilgrimage Sites in Shanku Maharaj's Bigalito Karuna Jahnabi Jamuna
}

\author{
Smitasri Joy Sarma \\ Research Scholar, Tezpur University, Assam. Email: smitasrijoyo5@gmail.com
}

\begin{abstract}
India is the land of 330 million deities, where religious establishments serve as landmarks for postal addresses, where people unite and divide on the pretext of religion, where every milestone involves religious ceremonies, where every birth, marriage or death undergoes holy rituals, or as Bengal endorses the nation's spirit as "Baro Mashe Tero Parbon" (13 festivals in 12 months). Though the nation speaks of religious diversities, India in the common psyche upholds Hinduism and its practices. In the Western literary bank, India is marked with sacred heritage that draws people to stimulate their spiritual, pursuing solace and the surreal. The legend of Shravan Kumar echoes the existing and common affair of pilgrimages in India that today proves as commercial, in fact as a lucrative sector. This paper endeavors to explore an Indian travel narrative in a pilgrim site through a close textual analysis of Khagendra Narayan Dutta Baruah's Assamese translation of Shanku Maharaj's Bigalito Karuna Jahnabi Jamuna (1962), originally written in Bengali in 1959. The text, though woven as a travelogue in a pilgrim site ventures to celebrate the humane, along with the divine. It evokes the reiterated statement of the journey as primal to the destination. The voice while capturing the ethos of India with all its nuances simultaneously dismantles and in fact challenges the conventional and romanticized vista of travelling, particularly in precarious sites. In India, treading the holy spaces despite usually accompanying itineraries can unravel into adventure as the lines blur between such accounts and otherwise.
\end{abstract}

Keywords: travel, pilgrim, pilgrimage, journey, nature

We are all pilgrims in search of the unknown

- Paulo Coelho

The belief of God residing within the self is a culturally ubiquitous concept. In a paradoxical vein, there prevails a relentless pursuit for the divine presence outside one, amid established infrastructure or natural disposition. India rejoices in the fact that it is home to the world's oldest religion, Hinduism. Though it typifies religious diversity, the Indian panorama primarily upholds Hinduism as its way of life. India boasts of an area of 3.287 million square kilometers, distinctive of topographical and socio-cultural oddities, yet from Kashmir to Kanyakumari it is bound by a common spectacle of religious affairs. Indian's preoccupation with mythology and its alleged synonymous idea of religion is best recorded during the broadcast of Ramanand Sagar's "Ramayan" in the late 1980s. The viewers practiced self-proclaimed lockdowns on Sunday mornings, hooked to their idiot boxes adorned with incense, lamps and garlands. Religion, thus, is the opium of the masses, promoted by home, society, institution or state.

Travel is the fulcrum of human civilization. Humans since the primeval ages have been constantly on the move, primarily on hunt for food and suitable shelter, to annex territories or escape probable intrusion. Akin to The Iliad or The Odyssey, a glance into the Indian epics, the Ramayana and the Mahabharata entail travel as an essential human condition. The Vedic

(C) AesthetixMS 2020. This Open Access article is published under a Creative Commons Attribution Non-Commercial 4.o International License (http://creativecommons.org/licenses/by-nc/4.o/), which permits non-commercial re-use, distribution, and reproduction in any medium, provided the original work is properly cited. For citation use the DOI. For commercial re-use, please contact editor@rupkatha.com. 
literature alludes to travel where God Indra elucidates the merit of travelling to King Harischandra (Bharati, 1963, p. 136). The Ramayana depicts the pilgrimage of Shravan Kumar who carried his old blind parents to holy sites. Across cultures, the trajectory of travelling posits pilgrimage as one of the earliest bases of journeying. Though pilgrimage is not compulsory in the Hindu religious fabric, a glimpse into Indian tourism, exhibits that many leading tourist attractions in the country bear religious significance. India as a site of spiritual enlightenment is rooted in the Western psyche as a network of gurus, sadhus, yoga, meditation, ashrams, temples, kirtans etc. underpins it. India is projected as a spiritual sanctuary, an escapade from the materialistic lifestyles and the concrete jungles. Episodes such as Elizabeth Gilbert's ashram stay or the Beatles' sojourn at Rishikesh and indulging in transcendental meditation reinforces such hypothesis. In common parlance, pilgrimage refers to "a sacred journey to a sacred place with a sacred purpose" (Rountree, 2002, p. 482). However, the Hindi equivalent of pilgrimage, tirthayatra is loaded with canonical Hindu doctrines and is upgraded from the former's fundamental denotation. The Sanskrit 'tirtha' means a crossing place or ford, while 'yatra' refers to a journey; hence it corresponds to travels marked by a river or other waterbody. A tirtha-yatra is defined by a visible external expedition whilst incorporating its adjunct of an internal journey of the traveller. S. M. Bhardwaj in his book cites the Skandapurana that refers to tirtha as "Truth, forgiveness, control of senses, kindness to all living beings and simplicity" (1983, p. 2). Hence, in this sense, pilgrimage attains a moralistic and secular attribute, not adhering solely to religious sway.

Jyotirmoy Ghosh Dastidar, alias Shanku Maharaj (1929-2004) adopting the mouthpiece Shravan Kumar offers another tale from his oeuvre pertaining to the Himalayas. His Bengali travelogue, Bigalito Karuna Jahnabi Jamuna (1959) set in the early post independence India, transports his characters as well as the armchair travellers to Gomukhi, the source of the river Ganges. It being one of the early documentations on the rough terrain is palpable as the tourist officer stationed at Rishikesh in the tale admits his limited knowledge about Gomukhi. This paper endeavours to examine travel narrative in an Indian pilgrimage setting encapsulating its kaleidoscopic range of thematic concerns. It will examine if the text conforms to the spiritual or religious agenda, with the destination under consideration. The study will engage in a close textual analysis of the translated Assamese version (1962) of the text with the same title by Khagendra Narayan Dutta Baruah (1939-2001).

The journey in question begins at Rishikesh and ends at Gomukhi, traversed primarily on foot. Though the mode of travelling hints at the inaccessibility of transportation, such treks are common even in contemporary times, believed as contributory to the pilgrims' devotion. The Himalayas, an embodiment of God Himavat, invites universal attention across India and abroad. In the popular imagination, fed on religious teachings, it has moved beyond the gargantuan geological structure and established as the abode of gods and goddesses of the Hindu pantheon, synonymous to Mount Olympus of the Greeks. Similarly, the river Ganges personified by Goddess Ganga, also the daughter of Himavat, is deemed as the lifeblood of Hinduism and Hindustan. The Ganges occurs in the scriptures and its perennial course stands testimony to the rise and fall of civilizations, thereby assuming an auspicious status in the collective unconscious. Many popular pilgrimage sites in India are centered on and around the Ganges and the Himalayas. Maharaj's amalgamation of the physical structures of an elevated land and a waterbody generates a saga that still casts a spell on readers and travelers.

The text opens with "Tathastu" (so be it) and the subsequent etiological account of Rishikesh. The mythological anecdote sets the tone of the text and prepares the reader for the upcoming content. Shravan Kumar, the narrator protagonist hailing from Kolkata is a learned 
man, well versed in myths and legends and secular politics and history. He is presented as an experienced traveller and particularly his familiarity with Rishikesh is explicit in his role as a short-term guide for a group of tourists. His scholarship aids as a narrative technique for the author to create an engaging account. One is refrained to view the places, shrines, rivers or ashrams occurring in the pages as mere backdrops but is immediately enlightened of their allied legacies. The locus of action, that is, present-day Uttarakhand is deemed sacred, an ideal distant destination for Hindus, thus promulgating the readers to anticipate it as a conventional pilgrim's journey. The place also referred to as 'Devbhumi', or land of the gods, bearing ancient associations is home to numerous Hindu establishments, thereby crediting it as a pilgrim hotspot.

The text manifests the enchantment of the place in the characters' arrival from all over the country and abroad, with diversified motives. Suman and Savitri undertake the journey to offer prayers at a particular shrine which they believe will heal the former's injured limb and the latter's husband's health. However, Kumar at the very outset admits his climb to the mountains is driven by the sensual feast nature has to offer and not to gain salvation. Lalaji, an elderly former businessman, through the pilgrimage seeks expiation for his son's inter-caste marriage. Karl Ulrich, a German national aims at experiencing the entire process of pilgrimage. He is a research student of Indian Philosophy at Munchen University; hence, the Indian pilgrim tradition would acquaint him with India's religio-cultural geography. The Cambridge Dictionary defines pilgrim as "a person who makes a journey, often a long and difficult one, to a special place of religious reasons." Thus, the text shatters this pigeonholed pilgrim narrative tradition, comprising of travellers as pilgrims seeking deliverance and travellers in quest for beauty, penance and knowledge in the same setting. The destination does not necessarily define or gauge the journey at all times.

The narrative not only revolves around the travellers but encompasses the residents of the localities on the way to Gomukhi. The digressions towards characters such as Anjali, her mother, Beena the doctor at Rishikesh, Masterji, Bhabiji etc. conjure to generate sundry accounts of piety, infidelity, goodwill, treachery, romance, domestic violence etc. along the central storyline. The vignettes of the fertilizer-deprived farmers, or the lawyer turned shopkeeper is emblematic of human plight and the constant struggle for survival. The episode of theft of Karl's belongings at Yamunotri or Chunri, her entrapment to prostitution and her murder is a paradox to the sanctified place. People throng to the sacred space to savour the undiluted atmosphere, distant from corrupt civilization; however, human nature is prone to decadence and recognizes no frontier. The life of Karl and the illustration of the bloodshed at his homeland further validate the universally susceptible human emotions and conditions. Kumar at times hints at the impact posed by independence and partition on people and the way certain populations are subjected to precarity. However, the multiple manifestations of humanity throughout the text counter it and fill the lacuna of the narrative.

The mythological retellings of Kumar bears semblance to the celebrated The Canterbury Tales (c. 1400). An overview of the journey delineates that it owes its feat to fellow beings and fellow feelings. Kumar and Ranjan are at the mercy of the fellow travellers for cooked food, shelter and even for the former's life. The text postulates that a pilgrimage is not solely an activity dedicated to the divine, but rather a celebration of humans and emotions. Along with the magnetism of Gods, pilgrimage is driven by a want of companionship. The site is endowed as a point of convergence for the individual and the community, and forms "a site of exchange, trade, social interaction as well as introspection" (Lane, 2017, p. 25). As Kumar believes it is far from a 
solo expedition as the road never guarantees it. There arises solidarity among the travellers owing to their common destination, irrespective of the labels of religion, language, class etc. (Maharaj, 1959/ 2006, p. 116). Hence, it endorses the axiom of the journey being significant over the destination.

The diegesis is a meditation on mortality. In the religious parlance, death in a pilgrimage site is reckoned as fortunate. In the text, the precarious terrain of Gomukhi is introduced by Anjali. Her established belief of Gomukhi as a place of no return evinces the intensity Kumar is to encounter. Since the inception of his journey, Kumar is bombarded with facts and figures of fatalities in Gomukhi. However, he is least apprehensive of death; and even prefers to die at the destination of his journey rather than in between (Maharaj, 1959/ 2006, p. 76). The trope of life as a journey reifies in Kumar, who wishes to accomplish it to a certain point that he considers his pinnacle. Kumar believes, in order to acquire nature's treasure one has to remunerate it accordingly (Maharaj, 1959/ 1962, p. 11). Hence, while pilgrims pay eclectic offerings to the holy river, Kumar complies by losing his beloved. Kumar's ease with the subject of death contests Suman's constant dread of losing her and Kumar's life. However, towards the completion of their journey, Kumar's nonchalant demeanour undergoes a metamorphosis as the fear of death seeps in as it might part him from Suman. Furthermore, the death of Suman reinstates how nature, like the Ganga and the Himalayas, withstand the ravages of time while human lives are transient and thrive only in nostalgia.

Any travel is backed by a motive, which may be utilitarian or otherwise. Irrespective of championing the objective or not, journeys tend to offer more than the expected outcome. Kumar is presented as a skeptic and nurturing a penchant for nature's bounty who ventures into the unknown and the unfamiliar, aware of every risk involved. He is astonished at Suman suddenly walking without any support, yet is skeptical to treat it as a mere miracle. However, Kumar is also established as a pilgrim, as Swami Tattabodh in the text says, the former's faith in the self parallels the belief in the divine. His love for Suman elevates him, as humans are part of nature, thus compelling him to imagine the creator despite his secular position. Kumar's journey is one of selfdiscovery, discerning the part of himself he was so far unconscious of. As Rumi says, "What you seek is seeking you." He apprehends the transience of human lives, learns to appreciate the spiritual and the immaterial, thus moving beyond mere perishable bodies. His journey draws him to enlightenment and demolishes his preconceived notion of pilgrimage as a mere extravagant institution. The transformative factor distinguishes a pilgrim from a tourist, as the latter primarily engages in a pleasure seeking activity.

Women characters, both travellers and settlers, populate the text. Kumar introduces pilgrimage as a space, far from the corrupt society, where humane gains primacy over the societal constructs of gender. However, it is observed that against the male travellers Kumar, Ranjan, Karl and others, women travellers have male company. Suman and Savitri are accompanied by the latter's brother. Even during their prior visit to Allahabad, Savitri's husband accompanies them. The difference is more palpable when Swami Anandji questions Suman's sudden change in the itinerary to proceed towards Gomukhi with Kumar and Ranjan, hardly sharing any familiarity with them prior to the journey. Suman, thus challenges the prejudiced idea of risk taking as a solely masculine exercise and ventures out towards Gomukhi. Her death owing to her fall through the ice seems to reinstate the conventional gender norms. The premise of women transgressing the stipulated sphere and landing in misery can be traced back to the episode of Sita's transgression of the lakshman rekha. Carl Thompson alludes to the long existing masculinist notions of women as a barrier in the protagonist's mission, belonging to alien cultures and mostly 
appealing figures (2011, p. 169). Though the thoughts of Suman once unsettle Kumar to tread the treacherous Goumukhi, Suman overthrows such premise by accompanying him, and in fact aiding him for his ill health and repeatedly saving Kumar from mishaps to accomplish the journey he had intended. Adhering to the mythological excerpts throughout the text, the unforeseen death of Suman seems to attain an analogous legend-like tragic status to which the place shall be a timeless witness.

The sadhus, pundits and swamis pervade the text but they refrain from displaying uniform traits. For instance, Swami Tattabodh rejects the stereotyped role of an ascetic as he intends to embrace domesticity and furthermore claims it to be onerous with relation to asceticism. Biswanath demonstrates his tryst with religion by serving humankind. There appear fraudsters who admit their pretence of palmistry and people resorting to trickery to dethrone the head of an ashram. The alarming sense of vulnerability restricts an unnamed ascetic to journey across Gomukhi which parallels him with Suman. Kumar's resolve to reach Gomukhi despite realizing the hazards also challenges the commonly held notion of the place as accessible only by the ascetics. However, the stay of ascetics at harsh seasons while commoner settlers flee the scene demonstrates their austerity against all odds. Moreover, the livelihood of most ascetics relied on the offerings made by the pilgrims.

Along with recurrent invocation to the past, the narrative is replete with rich live imagery. Through the eyes of Kumar, one encounters cascading rivers, serpentine roads, lush green valleys, wild flowers, snowcapped mountaintops, playful clouds, the drowsy sun and the bewitching moonlight. Even, at Gomukhi, the frozen canvas has to offer multiple shades of white. Though there occurs no spectral or material presence of the divine, nature acts as its proxy. On their way to Gangotri, Kumar and his companions enter a phantasmagorical state that propels Kumar to imagine it as paradise. Their path is suddenly obscured by clouds and except the blue sky; their sight fails to penetrate through it. The text is a paradigm of nature's grandeur, oscillating between its tranquility and its monstrosity. The pristine landscape at Gomukhi is startled by a storm before reclaiming its old state, symptomatic of the Hindu belief of the divine powers of creation and annihilation. The geographical figures are similar across countries that develop a sense of unity (Maharaj, 1959/2006, p. 105) and hence, a traveller in this sense is never foreign. Like every other entity, nature is subject to change. Apart from the human induced changes, Swami Sadanandji elaborates on the issue that the reconfigurations of nature is by nature itself. He illustrates it with the global instances, such as the receding temperatures of the poles, the shrinking glacial heights etc. that owes it to nature's innate whimsical cycle, thus personifying it. The text also highlights the way nature determines the lifestyle of a particular clime. For instance, at 2 p.m. Yamunotri lies in darkness while Kolkata bathes in daylight, engrossed in activities.

The genre of travel writing is no longer dismissed as a pleasure yielding apparatus, but caters to the dominant academic discourses, such as geography, history, political science, cultural science, anthropology, sociology etc. The multidimensional text under scrutiny corresponds to Maharaj's adherence to the refashioning of the genre. Apart from the religious influences, commentary on the socio-cultural, political and historical backdrop emits a complete picture in understanding the place. Thus, beyond the traditional religion motivated trips, such sanctified places also attract travellers to behold its intriguing heritage. The historical imprints on the place also underline the domain of religion as a persisting hotbed of conflict and a prime determinant of identity. The book also provides an appendix citing the walking distance from Howrah to Gomukhi, which at the period of composition was an instructive material. The text, placed in a 
foundational stage of Indian travel writing is pivotal in understanding the evolution of the genre over the years.

The travelogue forms an arresting negotiation of binary opposites: the road and the domestic, past and present, the individual and the collective, the material and the spiritual, sublime and chaos, love and loss, the humane and the divine etc. The text strikes the gamut of elements concerning travel writing, releasing it from the rigid classifications of the genre. Akin to spine-tingling travelogues, Bigalito Karuna Jahnabi Jaumna leads us to an adventure whose magnitude intensifies along with the trek. Even the most habituated ones are subjected to risk and at the mercy of nature's play. The travel made on foot, often on uneven paths exhaust the travellers and hence the journey period is extended. Apart from time consumption, one is ought to be cautious of narrow unsafe roads and wild animals. The adventure lies in that the travellers are aware of the uncertainties their lives are subjected to, yet accept the challenges. Pilgrimages are usually designed according to one's culture that incorporates some rules and objective-centric guidelines. However, the text hardly displays the rituals involved in it. The place of Gomukhi assumes the role of a character, mysterious and attractive, that people wish to encounter but seldom dare to materialize it. Suman strives for it and succeeds; hence, Kumar designates her death as heroic. The text, composed and published just a couple of years after independence highlights the troubles associated with travelling that adds to the adventure factor, in contrast to the modern day exercise of travel with advanced GPS, travelling accessories, housing facilities and primarily efficient modes of transport. In contrast to the toiling practice of the pilgrimage, the commercialization of the process has made it relatively unchallenging. As Kumar had anticipated, the sui generis essence of the road will be robbed by the ensuing technological advancements thus minimizing distance among places, but maximizing it among travellers (Maharaj, 1959/2006, p. 270). Today one need not undertake the arduous journey afar, for Ganga water is now available in packaged bottles at shops and online stores. One can opt for helicopter services substituting for the taxing trail. The spectacular sights of Gomukhi are available just a click away. The central and state governments also have adopted initiatives to cater to the pilgrims' needs. Human traffic both religious and secular, in pilgrim sites contributes significantly to the country's tourism revenue and hence a lucrative enterprise. Thus, travelogues in pilgrim sites call for a discourse to engage in the broad genre of travel writing, consisting of the journey, the destination, the travellers seeking their individual grails and returning with unique encounters, or forever lost in the no man's land.

\section{References}

Bhardwaj, S.M. (1983). Hindu Places of Pilgrimage in India: A Study in Cultural Geography, Religion, Asian Studies. University of California Press.

Bharati, A. (1963). Pilgrimage in the Indian Tradition. History Of Religions, 3(1), 135-167. https://doi.org/10.1086/462476

Lane, D. F. (2017). Sites of Encounter-Sites of Exchange: The Indian Pilgrimage in Contemporary Travel Narratives [Abstract]. Coldnoon, 6(1). https://coldnoon.com/journal/maple-september2017/the-indian-pilgrimage-in-contemporary-travel-narrattives/

Maharaj, S. (2006). Bigalito Karuna Jahnabi Jamuna. (Khagendra Narayan Dutta Baruah, Trans.). Lawyer's Book Stall. (Original work published 1959)

Rountree, K. (2002). Goddess Pilgrims as Tourists: Inscribing the Body through Sacred Travel. Sociology Of Religion, 63(4), 475-496. Retrieved from www.jstor.org/stable/3712303

Thompson, Carl. (2011). Travel Writing. Routledge. 